\section{A CASE OF RAYNAUD'S DISEASE ASSOCIATED WITH SCLERODERMA}

FREDERICK : P. MOERSCH, M.D. ANN ARBOR, MICH.

$\mathrm{Up}_{\mathrm{p}}$ to the present time we are still without definite knowledge regarding the etiology and pathology of Raynaud's disease and allied conditions. The present case offers some interesting features, for which reason it is

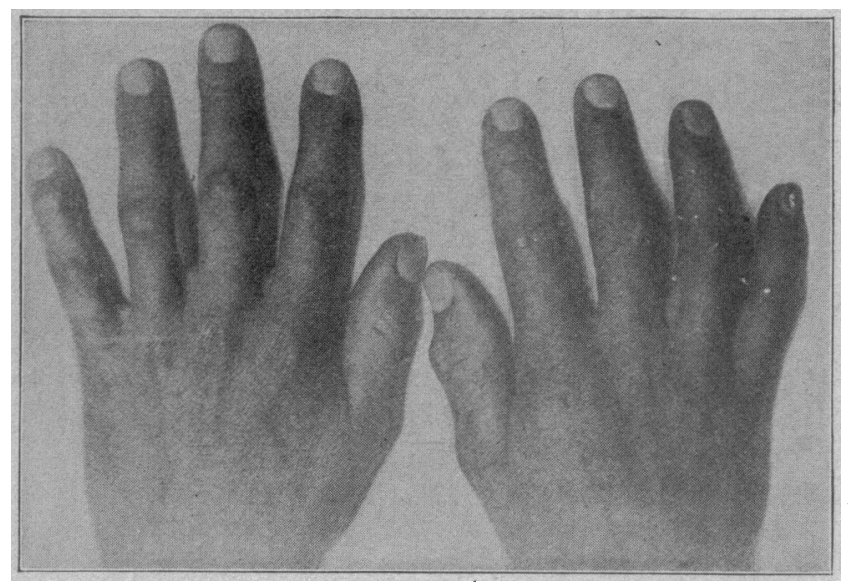

Fig. 1.--Nodules occurring over middle joints of fingers.

thought advisable to add it to the literature. It has been frequently noted in Raynaud's disease that there is a hereditary tendency. This, however, has not been determined in the present instance, and from our observations no definite etiologic factor could be established. Occupations and various trades have been mentioned as possible causes; but in the light of more recent investigation it does not seem that they have any definite relation to the disease. In the case here presented the factor of exposure enters; but it is questionable what part it played in the etiology. We have had this patient under observation from February, 1919, until a very recent date.

\section{REPORT OF CASE}

History.-The history as given by the patient is practically negative. There is no indication of any similar trouble in the family. Alcoholism is denied; there have been no cases of epilepsy, migraine or other nervous disorders either in antecedents or collaterals.

The patient was born in 1889 in New Mexico. As a child he was healthy and strong. He attended school up to the age of 18, after which he was employed in several positions, always making good money and never being discharged. $\mathrm{He}$ has been a moderate drinker, but never indulged to excess; a moderate smoker, and absolutely denies any venereal infection. $\mathrm{He}$ is married and has one living, healthy child. His wife is in good health and has had no miscarriages. Prior to entering the service, he was employed as a special officer for a trust company. In November, 1916, he was accidentally shot in the left thigh, making a speedy recovery. There is no history of tropical disease or other serious ailment. $\mathrm{He}$ has had no operations. In September, 1917, he entered the service, at which time he was in very good health, going to France in the spring of 1918.

Present Trouble. - The first indication of any trouble appears to have been evidenced by the man early in August, 1918. At that time his organization was in "support," having been in the trenches a few days before. It was during one of these days as he was writing a letter that he noticed a queer feeling in his fingers, and it appeared rather difficult to hold a pencil. On close inspection, he found that the knuckles of both ring fingers appeared somewhat swollen and blue. He gave this condition no special attention, considering it some passing and harmless ailment. August 5, a few days after he had noticed the first trouble, he was gassed and sent to the hospital because of some tung disturbance. He apparently recovered within a few days and was returned to duty, feeling about as well as usual. $\mathrm{He}$ believes, however, that following this experience his hands and fingers caused him more trouble. It seems that his hands would become cold and blue, and if he got chilled, the fingers would turn white and become numb. This condition continued for some months. At times it would bother him considerably, and again he would go days without any apparent difficulty. Oct. 7,1918 , he sustained a so-called shell shock, when he was confined to the hospital for one month. He returned to this country early in 1919 and has been under observation since that date.

Following his shell shock in October and while in the hospital, he believes that his symptoms gradually became more marked, that the other joints of his fingers became involved, and would become stiff, cold, swollen, and at times white. During his stay in the hospital, he developed a small mass on the sole of the left foot which was opened and a serum expressed. At the same time the heel of the left foot became black and numb, two small bluish white spots appearing in the center of this black mass. An incision was made, and apparently the discoloration vanished without any sloughing of the skin. He denies that he sus, tained any injuries to his extremities while in France, and does not believe that he was ever exposed to extreme cold, at least no more so than any of his comrades.

Examination.-The man was well built, and there was no general deformity. The.skin and mucous membranes were normal with the exception of the condition here noted. Physical and neurologic examinations were negative except for the findings here recorded. There were to be noted over the joints of the fingers on both hands, as shown in the accompanying illustrations, symmetrically placed indurated nodules which were adherent to the skin, but independent of the bone. These nodules occurred at the junction of the second and third phalanges. These were not painful, but

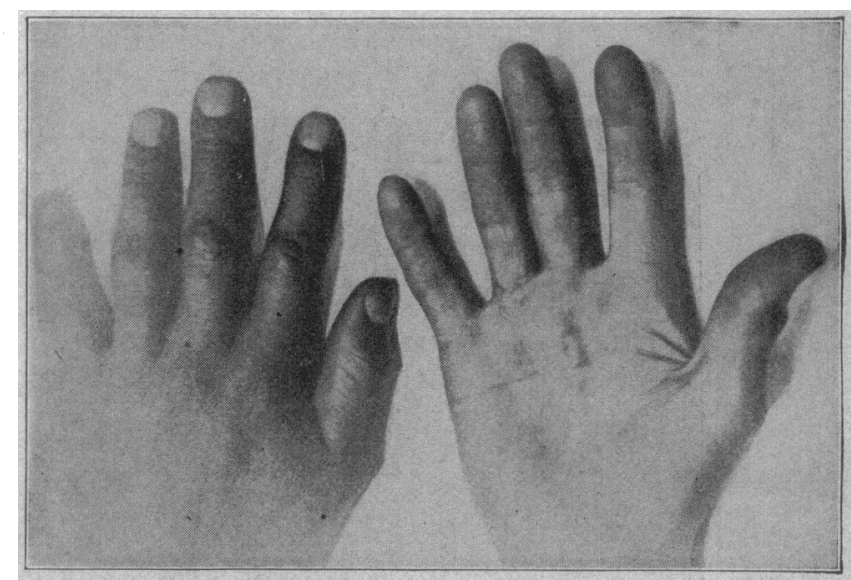

Fig. 2.-Induration along tendon sheath of middle finger.

appeared to cause a certain stiffness in the joints. Immediately over the masses, there was a slight impairment of sensation to touch and pin prick. There was to be noted in the palms of the hands an apparent thickening along the tendon sheaths of the third fingers which felt firm and indurated. There was also a mass on the sole of the left foot, while on the right foot there seemed to be the beginning of a similar condition. On several occasions, it had been noted that the fingers had become cyanotic, while at others, especially following a cold bath, the distal portions of the fingers had become white, during which time they would feel numb. Objectively, however, no definite change could be determiped. The urine examination revealed a faint trace of albumin on a few occasions. The blood Was- 
sermann reaction was negative on repeated examinations. The blood count was practically normal. Nasal smears on several occasions were reported negative. A section removed from one of the masses over the fingers showed a marked increase of fibrous and connective tissue, very much in the nature of a fibroma. Along the margins, which were rather vascular in character, many small bundles of connective tissue were noted. There was very little cell infiltration, and no acid-fast bacilli were found.

At the last examination, July 15 , it appeared that the patient's physical condition remained about the same. There were occasional headaches, and at times he seemed somewhat restless and irritable. The condition of his hands had gradually grown worse. The nodules had increased somewhat in size, and they were painful and caused considerable stiffening of the joints. As a result of this the thumb of the right hand could hardly be moved. The thickening, which confined itself to the palmar side of the hands and plantar side of the feet, gradually increased, and the mass that had made its appearance on the right foot was now fairly prominent. There were no added sensory changes. A roentgenray examination was probably negative.

\section{COMMENT}

The diagnosis of this case seems fairly certain. As to etiology, no positive factor can be ascribed. The history of exposure enters very strongly, but with so many individuals experiencing the same hardships, it does not seem fair to assume exposure as a causative factor. Thus, in spite of a negative history one may have to assume a neuropathic groundwork and an unknown exciting cause.

\section{AUTOTRANSPLANTATION OF THE KIDNEY *}

\section{CARLETON DEDERER, A.B., M.D., M.S. BAY CITY, MICH.}

In 1917, after-devoting several months to an experimental study of the elements of vascular suture, I attempted the autotransplantation of a kidney into the

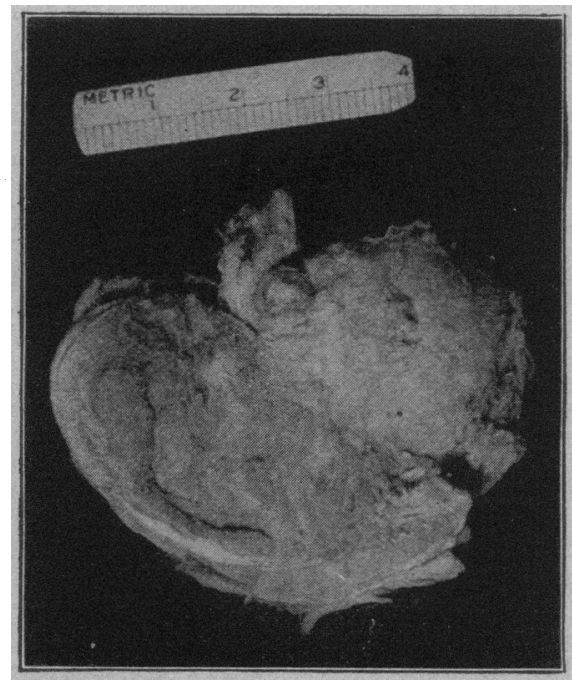

Fig. 1 (Dog B 976).-Autotransplanted kidney, removed from its site of functional activity in the neck on the one hundred and twenty-fifth day.

neck in the dog. After five partially successful operations, complete success was attained.

* Extract from thesis accepted by the Graduate Faculty of the University of Minnesota in partial fulfilment of the requirements for the degree of Master of Science in Surgery, June 19, 1919.
May 2, 1917, the left kidney of Dog B 976 was transplanted into the neck by uniting the renal artery at its bifurcation with the common carotid artery, and the renal vein to the external jugular vein. Some of the details of this experiment have been published. ${ }^{1}$

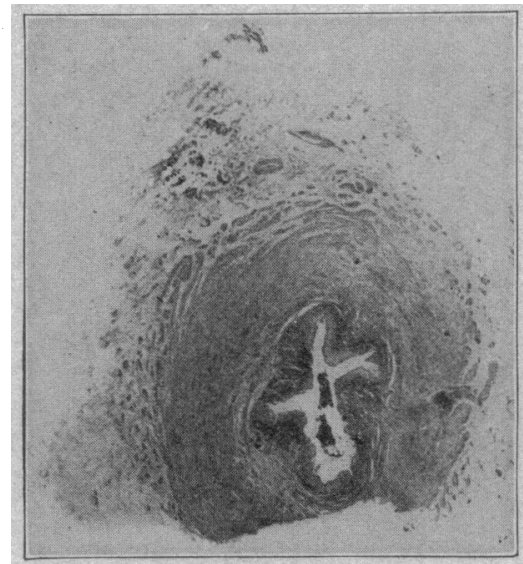

Fig. 2 (Dog B 976).-Cross section of the normal ureter on the one hundred and twenty-fifth day after operation; paraffin, hematoxylin and eosin; $x 15$.

Two weeks after transplantation, right nephrectomy was performed. The dog lived more than four months; it died as a result of hydronephrosis.

\section{EXTRACT FROM PROTOCOL}

Dog B 976.-Aug. 18, 1917, three months and sixteen days after the transplantation, and three months and two days after the second nephrectomy, analyses were made for comparison of the stream urine and of that which ran down

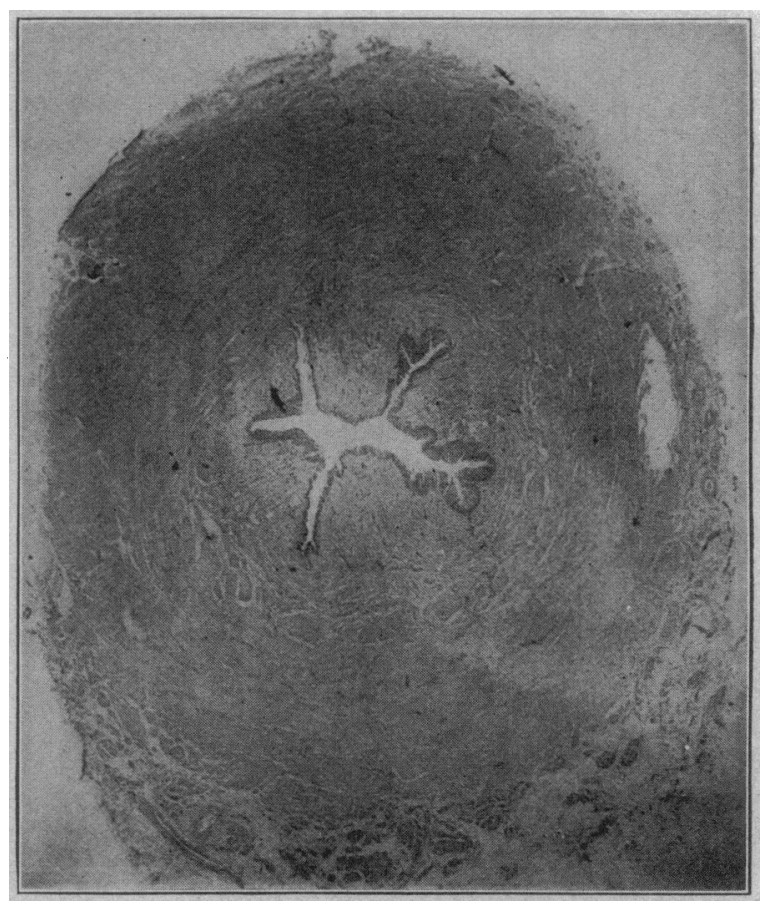

Fig. 3 (Dog B 976).-Cross section of the transplanted ureter on the one hundred and twenty-fifth day after operation, showing enormous hypertrophy in the transplanted ureter due to the obstruction at the meatus in the skin; magnified the same as Figure 2.

the animal's neck. The results of these analyses are given in the accompanying tabulation.

1. Dederer, Carleton: Studies in the Transplantation of Whole Organs, I, Autotransplantation of the Left Kidney to the Neck with Right Nephrectomy in the Dog, J. A. M. A. 70: 6-9 (Jan. 5) 1918. 